\title{
PROSPECTIVE STUDY OF AUSTIN-MOORE'S ARTHROPLASTY WITH BONE CEMENT IN FRACTURE NECK OF FEMUR IN ELDERLY
}

\author{
Mohammed Abdul Wahed ${ }^{1}$, P. N. Prasad², Ajay Kumar Pandey ${ }^{3}$ \\ ${ }_{1}^{1}$ Professor, Department of Orthopaedics, Shadan Institute of Medical Sciences, Hyderabad. \\ 2 Professor, Department of Orthopaedics, Shadan Institute of Medical Sciences, Hyderabad. \\ ${ }^{3}$ Assistant Professor, Department of Orthopaedics, Shadan Institute of Medical Sciences, Hyderabad.
}

\section{ABSTRACT}

\section{BACKGROUND}

Objectives - This is a prospective study of 40 consecutive cases of fracture neck of femur in patients older than 60 years who were managed by cemented hemiarthroplasty with Austin-Moore's prosthesis. The patients were followed up and the results were analysed with the objectives of studying the outcome of management of fracture neck of femur by cemented Austin-Moore's Hemiarthroplasty and to compare the results with standard studies using non-cemented Austin-Moore's prosthesis and to assess if cementing the prosthesis improves clinical outcome.

\section{MATERIALS AND METHODS}

40 patients aged more than 60 years, who sustained fracture neck of femur were treated by hemiarthroplasty using Austin-Moore's prosthesis and polymethyl methacrylate bone cement for stem fixation in Shadan Institute of Medical Sciences, Hyderabad, TS between December 2013 and November 2015; 40 patients who were followed up for a minimum of one year have been included in this study. Functional outcome was analysed using the Harris hip scoring system.

\section{RESULTS}

All the 40 patients were available for follow-up at the end of study period. The patients were in the age group of 68 to 85 years with the mean age of 74.7 years, $63.3 \%$ of patients were female with $90.9 \%$ of male. All cases sustaining the fracture following a trivial trauma. The functional outcome using the Harris hip score was excellent in $18 \%$, good in $50 \%$, fair in $13.6 \%$ and poor in $9 \%$ of the cases.

\section{CONCLUSION}

Hemiarthroplasty with Austin-Moore's prosthesis is a good option in elderly patients with limited physical demands and mobility. Cementing the prosthesis can achieve better control of thigh pain, improve mobility, allow early mobilisation and lesser use of walking aids. Cementing of Austin-Moore's prosthesis can be safely undertaken in patients to achieve better functional outcome.

\section{KEYWORDS}

Fracture Neck of Femur, Austin-Moore's Prosthesis, Bone Cement.

HOW TO CITE THIS ARTICLE: Wahed MA, Prasad PN, Pandey AK. Prospective study of Austin-Moore's arthroplasty with bone cement in fracture neck of femur in elderly. J. Evolution Med. Dent. Sci. 2017;6(17):1339-1343, DOI: 10.14260/Jemds/2017/291

\section{BACKGROUND}

Femoral Neck fractures are one of the most common in the elderly. The prevalence of these fractures has increased with improvement in life expectancy. The prevalence of the fracture neck of femur doubles for each decade of life after the fifth decade. ${ }^{1}$

With our society becoming more and more geriatric society, the burden of this fracture and its sequelae continues to be on the rise. ${ }^{2}$ The goal of treatment of femoral neck fractures is restoration of pre-fracture function without associated morbidity. ${ }^{3}$ Open reduction and internal fixation of these fractures in elderly has poor outcome including high rate of non-union and avascular necrosis.

Financial or Other, Competing Interest: None.

Submission 21-01-2017, Peer Review 13-02-2017,

Acceptance 20-02-2017, Published 27-02-2017.

Corresponding Author:

Dr. Mohammed Abdul Wahed,

12-2-823/a/86,

Fl. No. 301, Double Tree Apartment,

Santosh Nagar Colony,

Mehdipatnam, Hyderabad-500028.

E-mail:wahed35@hotmail.com

DOI: $10.14260 /$ jemds $/ 2017 / 291$
The introduction of single piece unipolar metal prosthesis by Thompson in 1954 and Austin-Moore's in 1957 to replace the femoral head ushered in the era of hemiarthroplasty of the hip as a treatment of these fractures. Experience of the last four decades has shown that hip Arthroplasty is the best treatment for intracapsular fracture of neck of femur in elderly in terms of both short-term and long-term results. ${ }^{4}$ Currently, surgeons can choose between unipolar and bipolar hemiarthroplasty and total hip arthroplasty in the treatment of intracapsular fracture of the neck of femur in the elderly. ${ }^{5}$

The problems encountered with unipolar prosthesis were acetabular erosion and loosening of stem giving rise to pain. Bateman in 1974 introduced the bipolar prosthesis, which had mobile head element and had additional head surface to allow movement within the acetabulum, this led to reduction of acetabular surface and hence reduce incidence of pain and acetabular protrusion, because motion is present between the metal head and the polyethylene socket (inner bearing) as well as between the metal head and acetabulum (outer bearing). 6

Bipolar prosthesis is slowly replacing the conventional unipolar prosthesis, because of its superior benefits as higher percentage of satisfactory results, less post-operative pain, greater range of movement, more rapid return to unassisted activity and reduced incidence of acetabular erosion.7,8 
We have taken up this study to gain deeper understanding of the results and problems associated with this procedure and to evaluate if using bone cement with the Austin-Moore's Prosthesis offers any distinct advantages in reducing the complications of thigh pain, stem loosening and periprosthetic fractures.

\section{Objectives}

1. To study the management of intracapsular fracture of the neck of femur with Austin-Moore's prosthesis used with polymethyl methacrylate bone cement.

2. To compare the results with standard studies and draw conclusions.

\section{Review of Literature}

Ambroise Pare, a French surgeon was the first person to describe fracture of proximal femur in $1564^{9}$ Emil Theodor Kocher suggested 2 mechanisms of injury in femoral neck fractures. The first was a fall producing a direct blow over the greater trochanter of femur.

The second mechanism is external rotation of the extremity. ${ }^{10}$ Sir Jacob Astley Cooper in 1882 was the first to distinguish between intra- and extra-capsular fractures. ${ }^{11}$ Union rate for close reduction and spica casting from the 1930 s recorded at only $23 \%{ }^{12}$

Attempts at internal fixation date back to isolated cases as early as 1850. In 1950s saw the advent of hemiarthroplasty as a means to prophylactically address non-union and avascular necrosis, the primary complications following femoral neck fracture fixation.

The Austin-Moore's $\mathrm{s}^{13}$ and Thompson prosthesis ${ }^{14}$ were successful metallic implants designed to replace the femoral head and neck secured with an intramedullary stem in the femoral shaft.

\section{The Evolution of Hip Arthroplasty}

The first reported hemiarthroplasty was by Delbet who used reinforced rubber as a replacement for the femoral head in 1919. In 1950, Thomson developed a short stemmed metal prosthesis. ${ }^{15}$ At about the same time, the Austin-Moore's prosthesis was described. This prosthesis had a femoral stem, which was fenestrated and also has a shoulder to enable stabilisation within the greater trochanter and to prevent rotation within femoral canal. It became apparent that the long-stemmed devices generally were superior to the shorter stemmed devices, which they soon replaced.

Beginning in 1973 and working independently, Giliberty and Bateman developed the prototypes of the current bipolar endoprosthesis, which used metallic cups lined with highdensity polyethylene that were locked securely on to the head of femoral component. ${ }^{16}$ Sir John Charnley began the development of various types of total hip replacement arthroplasties between 1958 and $1963 .{ }^{17} \mathrm{He}$ has ushered in the era of modern joint replacement surgery. 18

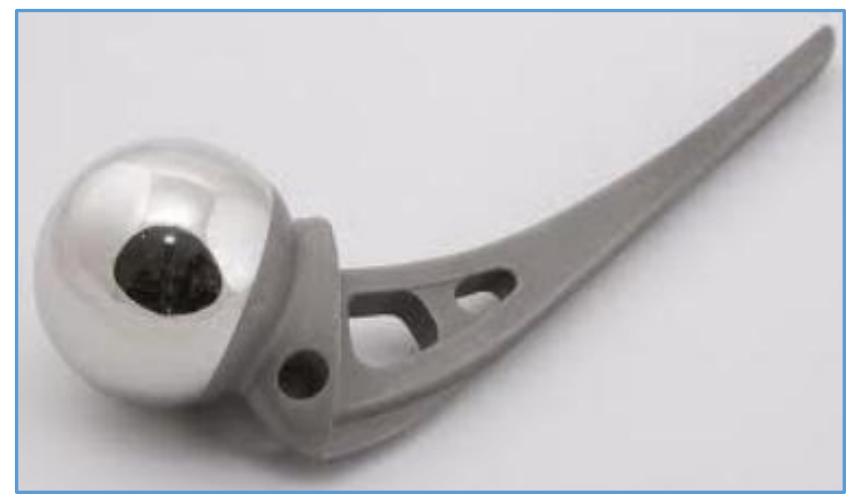

Figure 1. Austin-Moore's Prosthesis

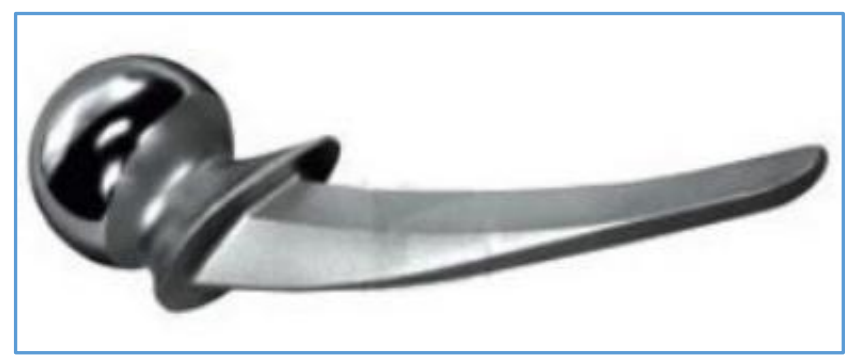

Figure 2. Thompson's Prosthesis

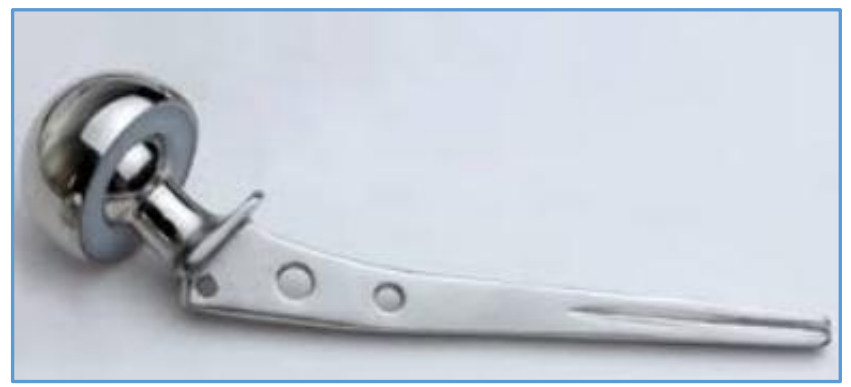

Figure 3. Bipolar Prosthesis

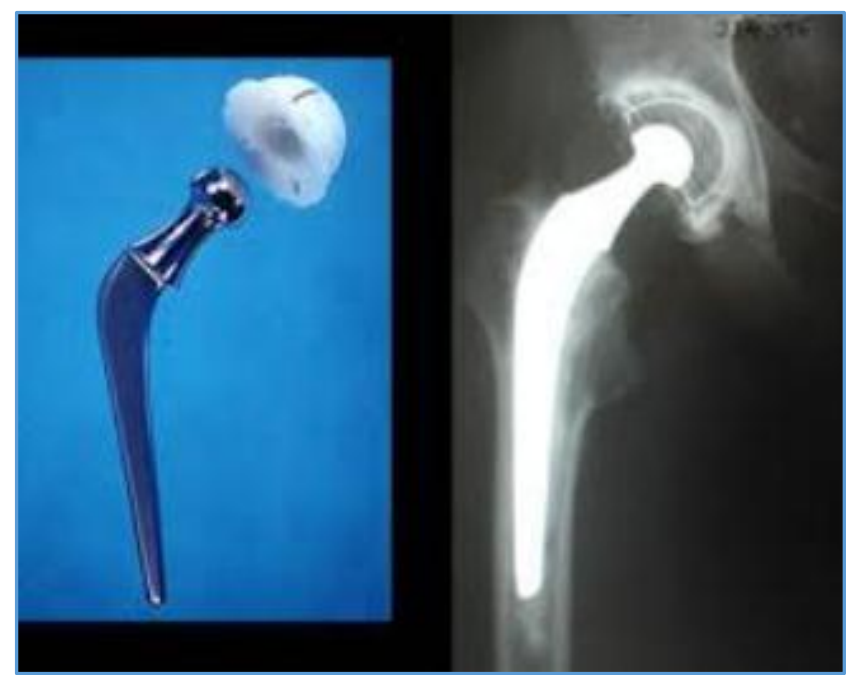

Figure 4. Total Hip Replacement 


\section{Use of Cement with Austin-Moore's Prosthesis}

The Austin-Moore's prosthesis is traditionally used without bone cement in contrast to Thompson's prosthesis, which is usually cemented in place. Charnley showed that the cement increases the weight bearing capacity by 200 fold. 19 The use of cement enables a secure primary fixation to be achieved at the time of surgery between the prosthetic stem and proximal femur. True fixation of an uncemented femoral component is less likely to develop with a hemiarthroplasty in a hip fracture patient than with a total hip arthroplasty in the arthritic patient. The intramedullary canal of the osteoporotic patient is likely to be wide and thin walled. ${ }^{20}$

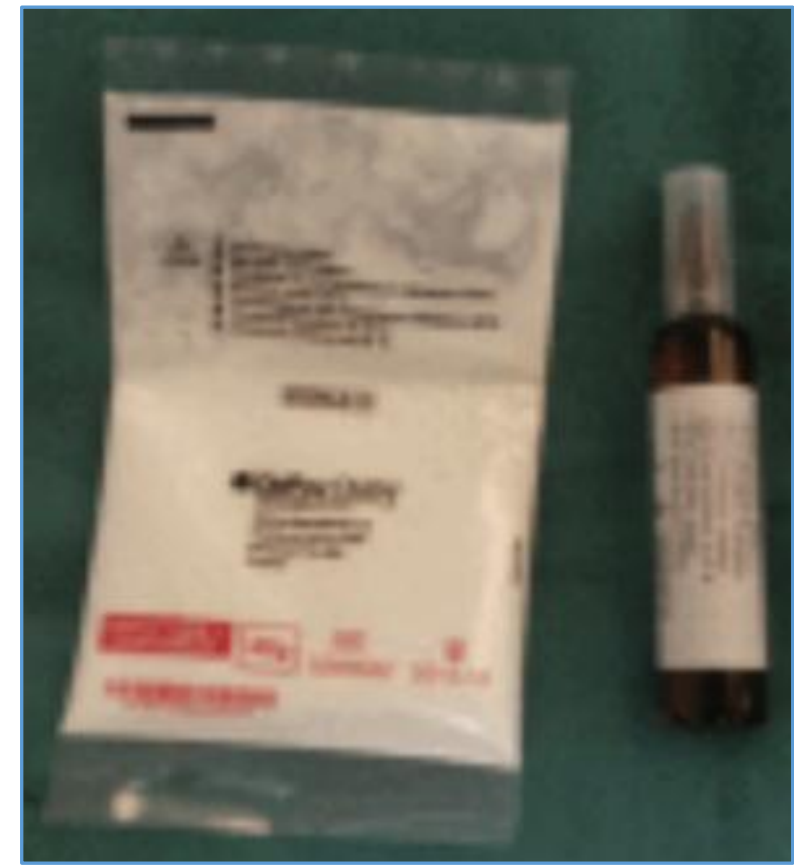

Figure 5. Powder and Liquid Components of Bone Cement

\section{Advantages of using Cement with AMP}

Follacci and Charnley (1969) reported a comparative study of a selected group of 40 patients. Half the patients were treated for complications of internal fixation of an intracapsular fracture by means of a Cemented Thompson prosthesis and half for a fresh fracture with uncemented Thompson prosthesis. The cemented group patients had less residual pain and improved gait. ${ }^{21}$

Lausten and Vedel (1982) found a slightly increased tendency towards loosening in uncemented prosthesis compared with cemented prosthesis at two years from injury in a group of 73 patients. ${ }^{22}$

Sonne-Holm et al (1982) compared Austin-Moore's arthroplasty with and without cement and found that the patients with cemented arthroplasties had a superior hip function during first 6 months of followup.

In this study, the Merle D'Aubigne total hip index was significantly higher for patients with cemented hemiarthroplasty, due mainly to less pain and better gait function. The authors attributed this to better primary anchorage. They also noted a higher number of settings in the uncemented group. ${ }^{23}$

\section{Safety of Cemented Hemiarthroplasty}

Although, there are number of advantages with using cement, it is associated with some serious disadvantages. These include cement-induced hypotension and cardiovascular collapse, excessive acetabular wear, difficult revision and retained cement within the acetabulum.

Sevitt (1972) reported a 7\% incidence of fat embolism in a series of 88 patients treated with cemented Thompson prosthesis for fracture neck of femur and none in those who underwent uncemented arthroplasty.

This was the sole cause of death in all patients within 1 week of injury. ${ }^{24}$

\section{MATERIALS AND METHODS \\ Source of Data}

40 consecutive patients with intracapsular fracture neck of femur satisfying inclusion criteria were admitted in Shadan Institute of Medical Sciences, Hyderabad - TS during the study period of December 2013 to November 2015 were included in this study.

\section{Inclusion Criteria}

1. Intracapsular fracture neck of femur.

2. Patients aged above 60 years.

\section{Exclusion Criteria}

1. Patients below 60 years.

2. Patients with arthritic changes involving acetabulum.

3. Pathological fractures.

4. Patients medically unfit for surgery.

\section{Preoperative Protocol}

All study patients were put on high tibial skeletal traction. Adequate medical management of comorbid conditions, informed written consent for the surgical procedure and inclusion for the present study was taken, standard surgical preparation was done.

\section{Surgical Procedure}

Cases were done under spinal or epidural anaesthesia. Moore's posterior approach was taken. 25

Standard surgical procedure was followed. The prosthesis of stainless steel AIS $316 \mathrm{~L}$ of 135 degrees and stem length of $127 \mathrm{~mm}$ and stem thickness of $10 \mathrm{~mm}$ was used; 40 gram of bone cement of Simplex P, Stryker Howmedica Osteonics Corp. NJ, USA was used.

\section{Postoperative Protocol}

All the patients were advised to sit with back rest from $2^{\text {nd }}$ postoperative day. Mobilisation with walker was started between $3^{\text {rd }}$ and $5^{\text {th }}$ postoperative day. Patients were initially advised toe-touch weight bearing and later advised progress to full weight bearing as tolerated. The study patients were discharged on an average of 40 days. Regular followup of all cases was done at 6 weeks, $3^{\text {rd }}, 6^{\text {th }}, 9^{\text {th }}$ month and one year. At each followup, patients were evaluated clinically using the Harris hip score and Radiologically. 

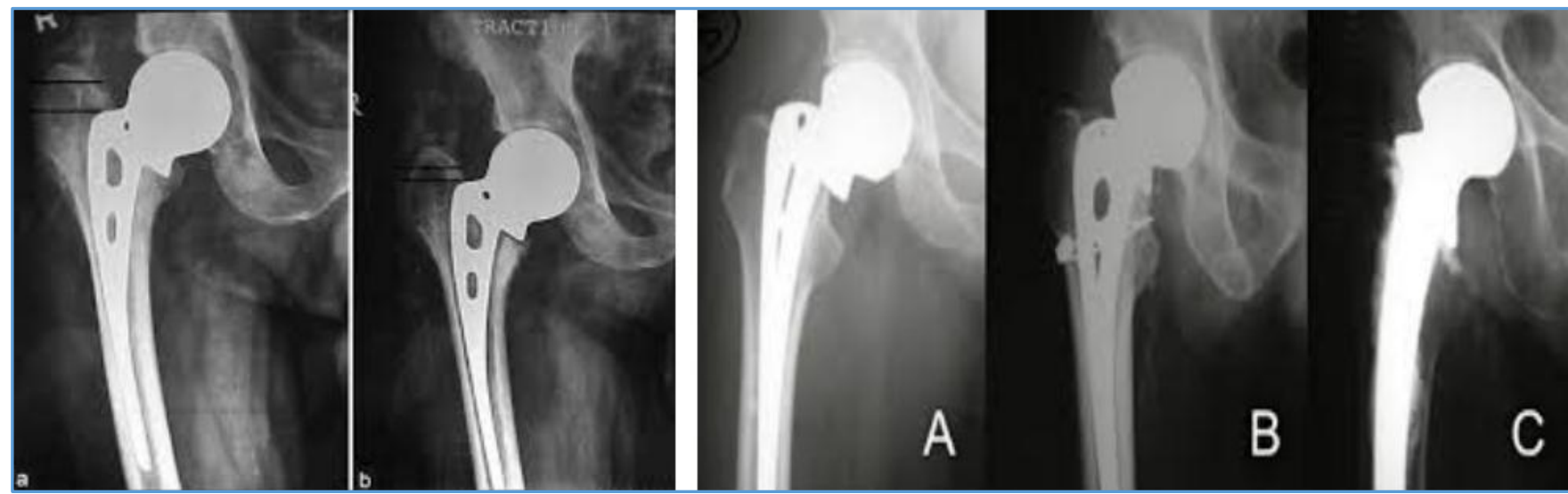

Figure 6 \& 7. X-Rays of Austin-Moore's and Thompson's Prosthesis In-Situ

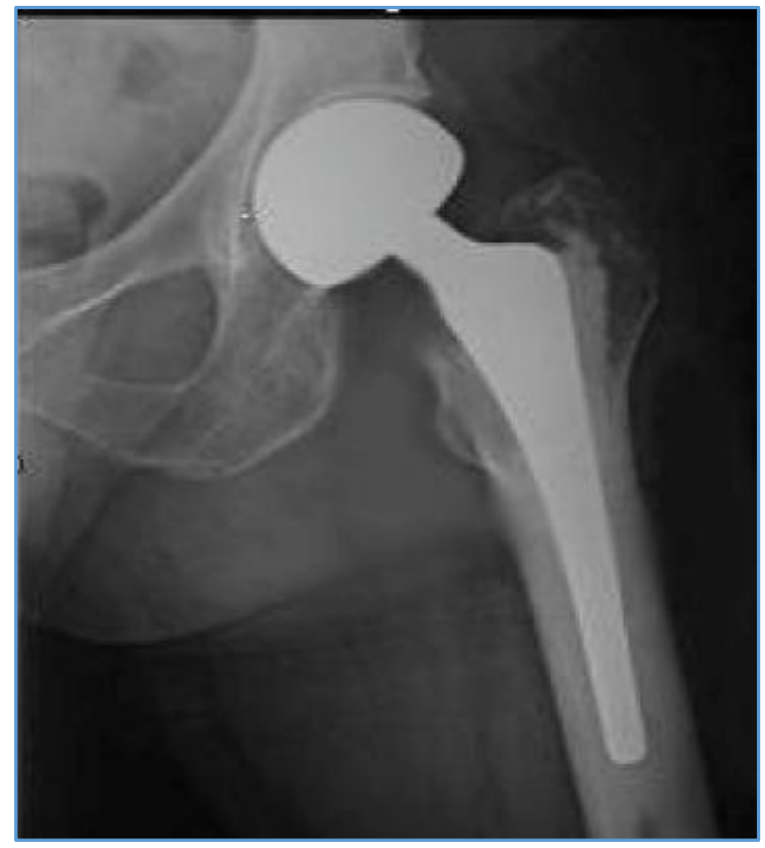

Figure 8. Bipolar Prosthesis In-Situ

\section{RESULTS}

\begin{tabular}{|c|c|c|}
\hline Age in Years & No. of Patients & Percentage \\
\hline $60-70$ & 6 & 15 \\
\hline $71-80$ & 29 & 72.5 \\
\hline$>81$ & 5 & 12.5 \\
\hline \multicolumn{3}{|c|}{ Table 1. Age Distribution } \\
\hline
\end{tabular}

\begin{tabular}{|c|c|c|}
\hline Sex & No. of Patients & Percentage \\
\hline Males & 15 & $37.5 \%$ \\
\hline Females & 25 & $62.5 \%$ \\
\hline \multicolumn{3}{|c|}{ Table 2. Sex Distribution } \\
\hline
\end{tabular}

\begin{tabular}{|c|c|c|}
\hline Mode of Injury & No. of Patients & Percentage \\
\hline Tripping & 36 & $90 \%$ \\
\hline RTA & 4 & $10 \%$ \\
\hline \multicolumn{3}{|c|}{ Table 3. Mode of Injury } \\
\hline
\end{tabular}

\begin{tabular}{|c|c|c|}
\hline Time of Presentation & No. of Patients & Percentage \\
\hline$<24$ hours & 11 & 27.5 \\
\hline $24-72$ hours & 11 & 27.5 \\
\hline 72 hours - 1 week & 6 & 15 \\
\hline$>1$ week & 12 & 30 \\
\hline \multicolumn{3}{|c|}{ Table 4. Time to Presentation after Injury } \\
\hline
\end{tabular}

\begin{tabular}{|c|c|c|}
\hline Radiological Type & No. of Patients & Percentage \\
\hline Trans-cervical & 36 & 90 \\
\hline Basi-cervical & 2 & 5 \\
\hline Sub-capital & 2 & 5 \\
\hline \multicolumn{2}{|c|}{ Table 5. Radiological Type of Fracture } \\
\hline
\end{tabular}

\begin{tabular}{|c|c|c|c|}
\hline Grade & Harris Hip Score & No. of Patients & Percentage \\
\hline Excellent & $90-100$ & 8 & 20 \\
\hline Good & $80-89$ & 24 & 60 \\
\hline Fair & $70-79$ & 5 & 12.5 \\
\hline Poor & $<70$ & 3 & 7.5 \\
\hline \multicolumn{4}{|c|}{ Table 6. Final Harris Hip Score } \\
\hline
\end{tabular}

\begin{tabular}{|c|c|c|c|c|}
\hline Grade & Our Study & Moore's & Jensen $^{\mathbf{2 6}}$ & Noor $^{\mathbf{2 7}}$ \\
\hline Excellent & $20 \%$ & $31.6 \%$ & $30 \%$ & $38 \%$ \\
\hline Good & $60 \%$ & $43.3 \%$ & $29.6 \%$ & $21 \%$ \\
\hline Fair & $12.5 \%$ & $16.6 \%$ & $43.3 \%$ & $24 \%$ \\
\hline Poor & $7.5 \%$ & $8.3 \%$ & $5 \%$ & $17 \%$ \\
\hline \multicolumn{4}{|c|}{ Table 7. Comparison with Standard Studies } \\
of Austin-Moore's Arthroplasty \\
\hline
\end{tabular}

\section{DISCUSSION}

The aim of replacement surgery in fracture neck of femur is early return to daily activities. This is particularly applicable to the elderly age group where complications related to prolonged immobilisation need to be prevented.

40 patients aged more than 60 years who sustained fracture neck of femur and treated by Austin-Moore's arthroplasty with bone cementing consecutively treated between Dec. 2013 and Nov. 2015 were included in the study at Shadan Institute of Medical Sciences, Hyderabad, TS.

The mean age of patients in the present study was 74.77 years. Present study also had a higher number of females; majority of our patients (90.9) sustained the injury due to trivial trauma. All study patients had a displaced fracture neck of femur. Majority had a transcervical fracture (90.90\%). When choosing hemiarthroplasty for management of fracture neck of femur, the age of the patient and time since injury is considered. ${ }^{28}$

A little more than half of our study patients were brought to the hospital within 3 days of sustaining the injury. All the study patients were taken for the surgical procedure between $3^{\text {rd }}$ and $5^{\text {th }}$ day of trauma. Most of our study patients were mobilised in bed on day 1 of surgery and with weight bearing as tolerated using a walker within the 72 hours of postoperative period. 
There was no case of any cement related complications like hypotension, pulmonary embolism or cardiac arrest.

The average duration of hospital stay among the study patients was 40 days. There were no postoperative complications like loosening, dislocation, erosion, subsidence, protrusio acetabuli or periprosthetic fracture.

In our study, the final Harris Hip score as evaluated in 1 year followup averaged 84.53.

There is only one study in literature by Sonne-Holm et al comparing Moore's arthroplasty with and without cement. The authors found that the patient with cemented Moore's arthroplasties had a superior hip function during the first six months of followup. In this study, the Merle D'Aubigne total hip index was significantly higher for patients with cemented hemiarthroplasty due mainly to less pain and better gait function.

\section{CONCLUSION}

Hemiarthroplasty using cemented Austin-Moore's prosthesis for fracture neck of femur provides freedom from pain, better range of movement and more rapid return to unassisted activity with an acceptable complication rate.

Providing a good primary anchorage in the osteoporotic femur is of paramount importance. This can be done by cementing the prosthesis without any significant increase in cement related complications. Our experience with AustinMoore's prosthesis has been better than that with an uncemented Austin-Moore's hemiarthroplasty. Considering the good result achieved in the short term, it seems reasonable to use bone cement for all Austin-Moore's hemiarthroplasties.

\section{REFERENCES}

[1] Leighton RK. Fractures of neck of femur. In: Rockwood and green's fracture in adults. Bucholz RW, Heckman JD, Court-Brown CM. (eds) $6^{\text {th }}$ edn. Philadelphia, Lippincott Williams \& Wilkins 2006:1753-91.

[2] Swiontowski MF. Intracapsular fractures of the hip. J Bone joint surg Am 1994;76(1):129-38.

[3] Ioro R, Healy WL, Lemos DW, et al. Displaced femoral neck fractures in the elderly: outcomes and cost effectiveness. Clin Orthop 2001;383:229-42.

[4] Bhandari M, Devereaux PJ, Swiotowski MF, et al. Internal fixation compared with arthroplasty for displaced fractures of the femoral neck. A metaanalysis. JBJS Am 2003;85A(9):1673-81.

[5] Ioro R, Schwartz B, Macaulay W, et al. Surgical treatment of displaced femoral neck fractures in elderly: a survey of American association of hip and knee surgeons. J Arthroplsy 2006;21(8):1124-33.

[6] Zofka P. Bipolar hip hemiarthroplasty. Acta Chir orthop Trmatol Cech 2007;74(2):99-104.

[7] Malhotra R, Arya R, Bhan S. Bipolar hemiarthroplasty in femoral neck fractures. Archives of Orthopedic and Trauma surgery 1995;114(2):79-82.

[8] Sud A, Sood LK. Bipolar hip replacement for displaced fracture neck of femur in elderly patients. Indian journal of orthopedics 1998;32:270-1.

[9] Baumgaertner MR, Higgins TF. Femoal neck fractures. In: Rockwood CA, Robert W, Bucholz, et al. Rockwood and green's fracture in aduts. $5^{\text {th }}$ edn. Philadelphia, Lippincott Williams \& Wilkins 2001.
[10] Protzma RR, Burkhalter WE. Femoral neck fractures in young adults. J Bone joint Surg Am 1976;58(5):689-95.

[11] A treatise on dislocationa and on fractures of the joints: fractures of the neck of the thigh-bone. Sir astley cooper, BART, FRS, surgeon to the king. Clin Orthop 1973;92:3-5.

[12] Fielding J, Wilson H, Zickel JR. A continuing end result study of intracapsular fractures of neck of femur. JBJS 1962;44(5):965-72.

[13] Moore AT. The self-locking metal hip prosthesis. J B J S Am 1957;39A(4):811-27.

[14] Thompson FR. Two and a half years experience with a vitallium intrmedullary hip prosthesis. J Bone Joint Surg Am 1954;36(3):489-500.

[15] Thompson JE. A prosthesis for the femoral head: a preliminary report. J Bone Joint Surge 1952;34A(1):175-82.

[16] Bateman JE. Single assembly total hip prosthesis: a preliminary report. Orthop Dig 1974;2:15-9.

[17] Charnley J. Total hip replacement by low-friction arthroplasty. Clin Orthop 1970;72:7-21.

[18] Steinberg DR, Steinberg ME. The early history of arthroplasty in the United States. Clin Orthop and Related Research 2000;374:55-89.

[19] Kankanala G, Gubbi SD, Pidikiti P. A comparative study of post-operative morbidity and mortality in femoral neck fractures in elderly patients treated with cemented and uncemented Thompson hemiarthroplasty. J of Orthopaedics, Trauma and Rehabilitation 2011;15:47-50.

[20] Parker MJ, Pryor, Glyn A. Hip fracture management. Oxford, Blackwell scientific publications 1993:129-46.

[21] Follacci FM, Charnley J. A comparison of the results of femoral head prosthesis with and without cement. Clin Orthop 1969;62(18):156-61.

[22] Lausten GS, Vedel P. The monk hard-top endoprosthesis for intracapsular fractures of the femoral neck. Injury 1981;13(3):233-8.

[23] Sonne-Holm S, Walter S, Jensen JS. Moore hemiarthroplasty with and without bone cement in femoral neck fractures. Acta Orthop Scand 1982;53(6):953-6.

[24] Rosborough D. Fat embolism in patients with fractures hips. Br Med J 1972;2(5812):528.

[25] Hoppenfeild S, DeBoer P. Surgical exposure. In: Orhtopaedics the anatomical approach. $3^{\text {rd }}$ edn. Philadelphia, Lippincott Williams and Wilkins 2002:365-454.

[26] Jensen SJ, Holstein P. A long term follow-up of moore arthroplasty in femoral neck fractures. Acta Orthop Scand 1975;46(5):764-74.

[27] Noor SS, Hussain N, Javid I. Outcome of austin-moore hemiarthroplasty in elderly patients with fracture neck of femur. J of Pakistan Orthopaedic Association 2010;20(1):14-9.

[28] Salvati EA, Wilson PD. Long term results of femoral head replacement. J B JS Am 1973;55(3):516-24. 